\title{
Getting to why? Contemplative practice as reflection on intentionality
}

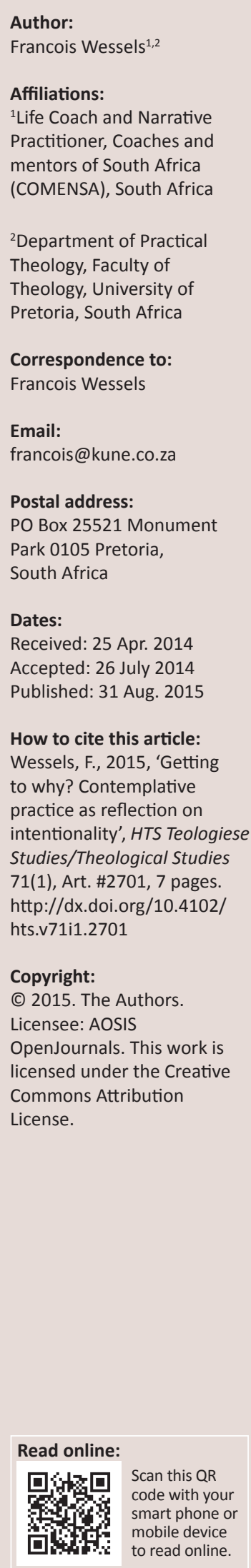

In my experience, conflict and other forms of being stuck or (as it is commonly referred to in narrative texts) 'stuckness' are related to actions, behaviour or events. If we consider a narrative paradigm, they happen in the realm of the Bruner's 'landscape of action'. Efforts at escaping these problem-saturated experiences mostly resort to replacing these actions, habits, modes of operation or rules with a different set of rules, without first reflecting on the intentionality or 'why' behind the actions. Most often this only serves to perpetuate the problem. This article will attempt to show that alternating between various initiatives in the 'landscape of action' provides only temporary respite to the problem, if any; that the intentionality behind these actions needs to be revisited and that contemplative practice facilitate such reflection on intentionality. This is therefore an exercise in reflecting on intentionality or even purpose, that is, a teleological question. This process traverses the dimensions of 'what' (actions), 'how' (methodology) and 'why' (intentionality), referring to the biology of human decision-making in the process of doing so. This article posits that this reflection may be facilitated by contemplative practices such as mindfulness and reflecting on soul.

\section{Introduction}

\author{
To say that all human thinking is essentially \\ of two kinds - reasoning on the one hand, \\ and narrative, descriptive, contemplative \\ thinking on the other - is to say only what \\ every reader's experience will corroborate. \\ William James (quoted in Bruner 1986)
}

This is most people's reality: As soon as something is perceived, it is named, interpreted, compared with something else, liked, disliked, or called good or bad by the phantom self, the ego. They are imprisoned in thought forms, in object consciousness. (Tolle 2009:239)

When we reflect on problems we experience - whether these are organisational or personal - it often occurs to us that these problems are situated within behaviours, actions, rules, traditions or events in the activity dimension of life rather than the implicit meaningfulness dimension. In this article, it will be suggested that this may assist in explaining confrontation and conflict, both intrapersonal and interpersonal.

Trying to resolve these problems, experience from my practice seems to indicate that our default strategy is to search for alternative behaviours, actions, rules, traditions or events, thus really only expanding the system and not presenting any transformative solutions. This sentiment is supported by some comments by White (2007:263, 266 inter alia). Any relief to the problem experience produced in this way is quite often partial and of limited duration (Figure 1).

This reminds of the old workhorse, Boxer, in George Orwell's (1979) Animal farm. His solution to any problem was always 'I'll just work harder'. This may result in 'more of the same' or a policy of 'more is better'. Benner (2011:147) refers to the 'busyness' which we may adopt as a strategy to cope with problems in our lives. The Economist quotes Wiley Hausam (2014), the executive director of Stanford's new Bing Concert Hall, referring to the workplace as a 'rat race' in which we are in a constant 'state of distraction'. Webster (2002:1) indicates that despite the apparent affluence associated with 'increasing quantitative aspects of [their] lives such as material wealth and longevity', Australian people (and most of Western civilisation), are not experiencing an improvement in their quality of life. In a strongly-worded statement he suggests that: Often this material abundance can be seen to be 'just a waste of time' if it fails to promote the value of existence (Webster 2002:1). 


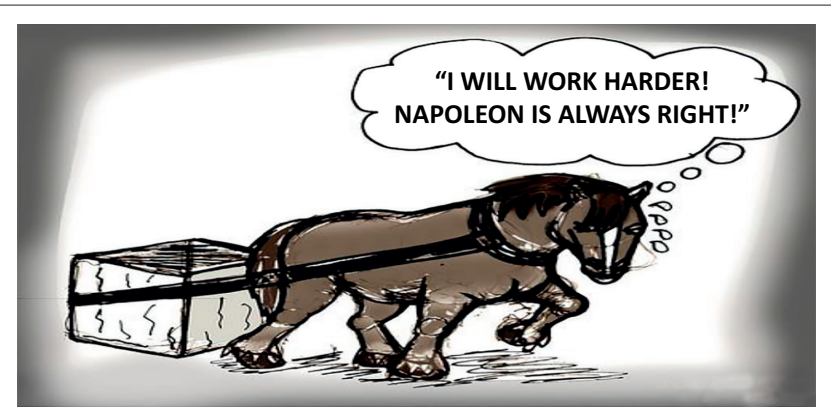

Source: Bell, J.W., 2009, 'I will work harder! Napoleon is always right!', viewed 26 August 2015 from http://userscontent2.emaze.com/images/5a5e98ab-70eb-4f34-b53f-48b7834f4403/ from http://userscontent2.emaze.com/imag

FIGURE 1: The boxer's philosophy.

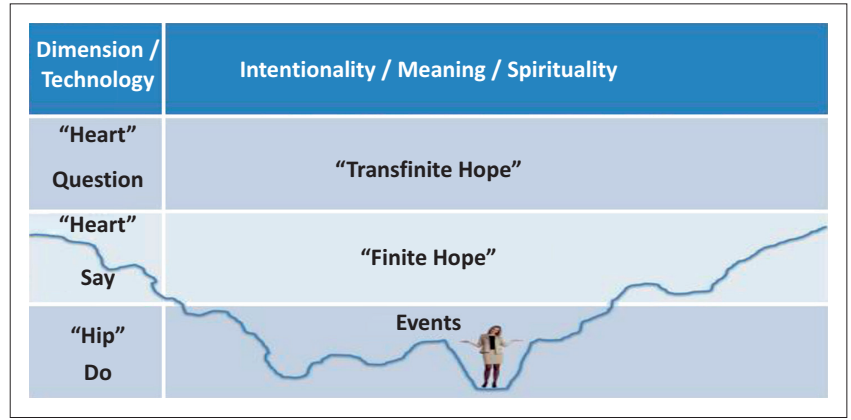

FIGURE 2: Technologies of problem solution.

Quoting Buttrose, Webster (2002) continues:

This era of uncertainty in the midst of apparent economic prosperity, has witnessed a state of national pessimism develop in this country for which the development of spirituality is seen as offering a potential solution. (p. 2)

We may refer to this approach to problem solving as actionbased strategy. Sami Pihlström in his 2007 article discusses the action-based strategy as it refers to a quest for meaning, comparing it to a contemplative approach as he does.

If we were to analyse the problem situation, it might lead to a rationalisation of the problem and new designs and plans might result. This is often associated with advice being given and may produce another set of potential solutions. This may be referred to as analytical strategy or methodology strategy. The potential solution technologies resulting from this approach may be more numerous and provide longer-lasting relief. From personal experience in my practice, this may be the most common approach to problem solution in our society.

It is only when we start to ask ourselves the question 'why?' that the implicit meaning behind the problem experience is discovered. This provides an understanding of the reason why we are experiencing something as problematic, revealing what beliefs, hopes, dreams, passions, purposes and intentions might be frustrated by the problem scenario. This requires reflection, interpretation and a certain scaffolding process as suggested by White (2007:9ff.). The process takes us from the landscape of action (Bruner 1986:14) to the landscape of consciousness or, as I prefer to refer to it, the landscape of intentionality. This may be called an intentionality strategy. These technologies are illustrated graphically in Figure $2 .^{1}$ This suggests a teleological imperative, that is, the requirement to reflect on purpose or intention.

Getting to the 'why?' is, however, not always easy for clients, perhaps because of reasons like 'cognitive clutter' or overthinking (resulting from an analytical strategy), or simply because they have never embarked upon a hermeneutical pilgrimage or a journey of interpretation and understanding to discover their own intentionality in the problem context.

As has become evident above, this article is positioned within a narrative approach. That implies that it assumes that we story our lives or that our realities may be constructed narratively. Most of the work done within this paradigm relies heavily on language and linguistic constructs. The structuralist nature of language may however be limiting in reflecting on meaning and significance. As such, language may be considered to be not only a meaning generating technology, but also a means of control and a power technology. I would like to propose that it is in the attempt at ontological control of meaning and a meaningful life that a certain reduction in meaning takes place, and that the full significance of awareness may reside in that moment before interpretation and 'languaging' of understanding. To become fully aware of this significance and perhaps discover our own intentionality in what we experience, we may therefore have to resort to or include non-linguistic practices.

The author would therefore like to posit that contemplative practices like mindfulness, meditation and similar awareness or consciousness approaches may facilitate this process of accessing the meaningfulness or intentionality implicit to the problem experience. In the process the article will indicate that the 'why' or intentionality can be explained biologically to reside in the primitive brain; that this primitive brain or limbic brain is not sensitive to language; that this may provide a challenge for the language-based narrative approach; that intentionality is centred in the limbic brain; that contemplative practices are a limbic activity and that

1.This figure was developed while working with clients in couples therapy, hence the reference to 'Hip', 'Head' and 'Heart'. The schematic representation suggests that we sometimes get stuck in practices within the social system of which we are members, whether that is a marriage, the workplace or any organisation within which we play a role. This is much like a little player in a computer game being stuck in the crevices of the landscape which it has to navigate. As was explained above, the crult recourse is to try and find an alternative action, another practice to the default recourse is to try and find an alternative action, another practice to replace the problem practice. This may elevate the player in our computer game somewhat, but its freedom of movement will only improve somewhat and the ad' exercise, rationalising the problem may once again lift the player from its problem context, but even this problem-solving technology may have limited success. In a world infused with linear logic, this has become a very popular approach and has developed the ' 3 steps to success'-industry swamping the shelves in bookstores. Evidence of the shortcomings of this approach lies in the very existence of the therapy profession. If we could merely rationalise our problems, reaching solutions through cognitive tactics, no professionals in the helping professions would be required! The approach can therefore be said to result in 'finite hope' (see also Lester 1995:62) based on 'finite objects, desires and processes', like acceptance of a certain graduate program, an upturn in the stock market or a pay increase.If we were to go to the 'heart' of the matter, however, reflecting on the intentionality of the practice or the 'why' the landscape would open up, offering various of the practice or the "why, the landscape would open up, offering various possibilities of agency. This will require that we question the processes or practice rather than assume that we know what they are all about. As a result, we will gain access to 'transfinite hope' (Lester 1995:64). This refers to meaning beyond the physical, mechanistic and material that is the realm spiritual. This is an appeal for becoming still and reflecting, rather than blundering on in a dogged fashion, blinkered to the consideration of alternative approaches or ways of being. 
contemplative practices may therefore provide a potential solution for accessing the intentionality implicit to our social behaviour.

\section{Problem-saturated stories}

[Three umpires] are sitting around over a beer, and one says, 'There's balls and there's strikes, and I call 'em the way they are.' Another says, 'There's balls and there's strikes, and I call 'em the way I see 'em.' The third says, 'There's balls and there's strikes, and they ain't nothin' until I call 'em.' (W.T. Anderson quoted by Freedman \& Combs 1996:19)

In this article I shall adopt a social constructionist - or a relational constructionist epistemology - as I prefer to think of it. This implies that meaning is generated within the relationships we form and maintain. Relationship, here, is used in a very generic sense of the word, referring both to our social position in the association with other people as well as to social structures and discourses.

Central to this paradigm are ideas like:

- realities are socially constructed

- realities are constituted through language

- realities are organised and maintained through narrative

- there are no essential truths (Freedman \& Combs 1996:22).

When I am using the word 'discourse', I am referring to all those taken-for-granted truths which we have accepted and dare not even question for fear of starting the unravelling of the fabric of our coherent existential securities in our thinking; one thread becoming undone may just lead to the next and so forth. These discourses are potential areas of meaning to be explored by means of deconstruction processes. In this sense we may have to consider how deconstruction can be employed to explore different understandings of these discourses without removing all our securities. This will be addressed when reflecting on the apparent need to remain congruent to our selves whilst entertaining the possibility of change.

If we assume that there is a requirement of unity or coherence in establishing our sense of selves (Parry 2009:9), we may utilise a narrative framework to provide us with a narrated identity. Narrative can be understood to consist of:

- experiences or events

- arranged sequentially

- over time or chronologically

- according to a coherent theme or plot (Morgan 2002).

According to Bruner (1986), events from the set of activities or 'landscape of action' are interpreted ${ }^{2}$ to derive the inherent meanings, hopes, dreams or intentions which in turn become part of the meaning dimension or identity plane, which he calls the 'landscape of consciousness' or which we can call the 'landscape of meaning'. We can therefore think of human beings to be interpreting beings or homo sapiens as homo hermeneuticus (see Bruner 1986:7 in this regard). This hermeneutical process can be understood to be a meaningmaking process.

The interpretative framework for this hermeneutical process is relational or social. This process is therefore not an individual endeavour - which may easily lead to a position of cogito ergo sum or a Cartesian ontology, in other words reducing life's meaning to that which can be thought or understood - but intimates that meaning is socially constructed within our social networks, politics and culture (see for instance White 2000:37).

\section{Functioning from a space of intentionality}

$[I] \mathrm{t}$ can be posited that narrative is an ongoing temporal process from which can emerge other processes, of dialogue, intentionality, consciousness of the world and of other, conceptions of temporality beyond that of lived experience, and ultimately personal identity. (Rankin 2002:2)

In contrast to 'internal state understandings' which suggest that our actions are the 'surface manifestations' of 'essences of a self' (cf. 'human nature', personal traits, personal characteristics), which can be discovered at the core of identity (White 2007:101), 'intentional state understandings' posits that we are living out our lives according to intentions which we embrace in the pursuit of what we give value to in life (White 2007:103). According to White (2007), the former may lead to:

- the development of the humanist notion of human 'nature' as foundational to human existence and the source of human expression

- the evolution of 'self' as essentially central to personal identity

- the displacement of 'moral judgement' by 'normalising judgement' (p.102).

Intentional state understandings are also distinguished by the notion of 'personal agency' (White 2007:103). Agency is described by Drewery (2005:315) as participating in the conversations that produce the meaning of our lives. Once again the link between intentionality, meaning and agency becomes apparent. White $(2007: 103)$ also suggests that the intentional understanding of meaning enables us to become 'active mediators and negotiators of life's meanings and predicaments'. This may happen individually as well as collectively or in organisations. Following White (2007), thus both for individuals and organisations this notion of identity may become the foundation of:

- the development of a sense of life being joined with the lives of others around shared themes

- an experience of being acknowledged about one's own life, be that individual or organisational

- the expression of the experience of some of the neglected but significant events, both positive and negative (in this regard, see also Briskin 1998:33-63) 
- speculation about the value others might perceive in the life and identity of the individual or organisation

- changes in actions available which would be in harmony with what he, she or the organisation gave value to

- expression of the manner of engagement with these intentions and values (pp. 105-106).

\section{The need to reflect on intentionality - the Why imperative}

Nothing motivates us humans more than meaning (Wheatley 2007:165).

As was suggested above, when we reflect on problems we experience, it often occurs to us that these problems are situated within behaviours, actions, rules, traditions or events in the activity dimension of life rather than the implicit meaningfulness dimension.

These behaviours, actions, rules and events can be said to be discursively positioned (see inter alia Kure 2010:26ff.; Winslade 2003:72ff.; 2006:502ff.) relative to the dominant discourses within the social system. Discourses here refer to those taken for granted 'truths' in society which we mostly do not even question as to their validity. In this discursive positioning some of the actions may be privileged, being positioned in such a way that they are positively aligned with the dominant discourses within the social system. Who is allowed to say what in any social context may be dictated by power discourses within that social system and lead to colonising of meaning (Drewery 2005:307-308, 310)?

When we do not reflect on the intentionality of our actions, rules or traditions, these may become reified ${ }^{3}$ and assume the status of the only legitimate possibilities (Drewery 2005:306). Once detached from its rooted meaningfulness, the rule, tradition, action or way of life may assume an almost untouchable status, and any changes to it may evoke the fear of starting the unravelling of the whole meaning tapestry. Sustaining these rules, traditions or modi operandi therefore becomes more important than their implicit purpose.

If we assume that there is an ontological need for us to 'stay true to ourselves', to be assured that our lives make sense, a certain coherence or congruence might be required. This implies that we need to be able to consider our life events and discern a common theme, pattern or developmental progression. If we therefore resolve to approach problems by mere substitution of a set of actions or rules by another, without having reflected on the intentionality implicit to this set, we also risk forfeiting the coherence of these actions. Detached from the 'why', these actions may therefore risk becoming a loose bundle of rules and potentially meaningless as such. In turn, we may therefore

3.Reified as it is used here is derived from the Latin word ' $r$ 's' meaning thing (German Verdinglichung), and refers to the dynamic which develops when a discourse is removed from its context and assumes a certain untouchable ('free radical') nature. As such the associated power effects may be very significant and sometimes even become toxic.

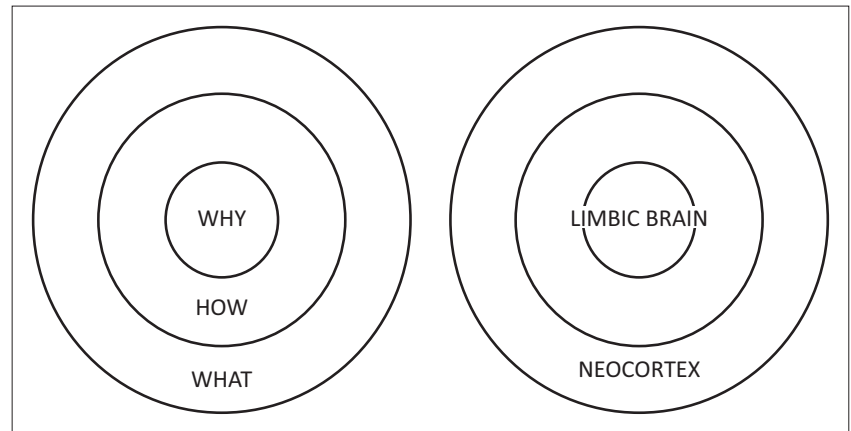

Source: Sinek, S., 2009, Start with why: How great leaders inspire everyone to take action, Penguin Books, Johannesburg

FIGURE 3: The Golden Circle as Developed by Simon Sinek.

once again revert back to doing more and committing to actions favoured by the dominant discourses in business and society, like working harder, earning more, measuring up to our perceptions of societal standards or making sure that at least on the surface everything is orderly and seemingly under control.

In his seminal work, Simon Sinek (2009:37) develops the concept of the 'golden circle' in which he indicates that people are engaged and motivated not by the 'what' in our messages. According to this theory, what we can offer and how good that is will not enable people to engage in a way which will change behaviour and ensure sustainable transformation. Short term changes might be effected, but as soon as the next attractive offering comes along, behaviour might change again. By referring to examples from commerce (Apple), politics (Dr Martin Luther King) and innovation (the Wright brothers), he illustrates how a shared belief more than anything else manages to engage and motivate us. This is represented in the three concentric circles in Figure 3, where he refers to the 'what' (the 'surface' offering), the 'how' (methodology) and the 'why' (intentionality, significance, meaningfulness and belief). Communicating 'from the outside in' (that is, starting with the 'what'), Sinek (2009:55) posits that 'people can understand vast amounts of complicated information, ..., but it does not drive behavior'. If on the other hand we communicate from what he refers to as the 'inside out', therefore starting with the belief, the intention or the 'why', Sinek (2009:55) suggests that the part of the brain which controls decision-making is directly engaged. This he explains by referring to brain biology. As is evident in Figure 3, when human decision-making is described biologically, there is a definite parallel in that the 'what' is governed by the neocortex, while the 'how' and more specifically the 'why' (or intentionality) is a limbic brain function. In this regard see also Freeman (1994, 1995) as quoted by Jerome Iglovitz (2001) in his article on consciousness. Figure 3 may now be revisited to include this information. Figure 4 presents our new understanding.

Sinek (2009:55) points out that the primitive brain (including the limbic system) does not have the capacity for language and it is this disconnect that might provide a challenge when we try and express our feelings in words. This may then 


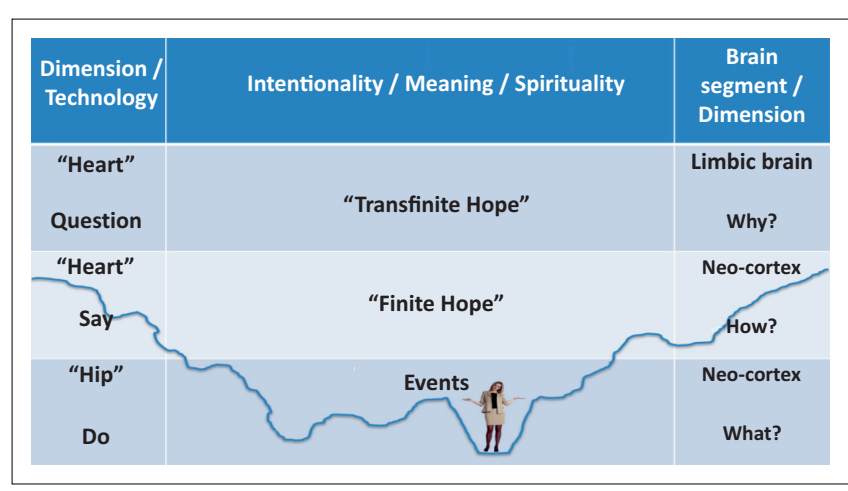

FIGURE 4: Technologies of problem solution revisited.

explain why our clients may find it difficult to access the intentionality implicit to their actions, behaviour, rules and traditions. This may lead us to conclude that narrative approaches, with their strong language base, may encounter problems in getting to the intentional. White (2007:53-54) discusses some problems which may be encountered in entertaining the 'why?' question; how it may be deferred initially and how these challenges may be approached. If this is accepted, we may then have to complement the narrative approach with other practices to access this intentionality. The next section will suggest one such practice when it introduces contemplative practices as a potential complementary approach to story.

\section{Contemplative practice as means to reflect on intentionality}

Contemplation as used in this article will refer to the family of spiritual and contemplative practices including meditation, contemplation, mindfulness and reflective practices. Following Blanton (2007:212), contemplative practice is understood to refer to 'ways of freeing the mind from thought'. Referring to Kabat-Zinn (1990), Blanton (2007:213) describes mindfulness as 'intentionally focusing one's attention on the experience occurring at the present time in an accepting way.' Whereas stories are central to narrative practice, silence is the soul of contemplative practice. Siegel (2007) says that:

Why silence? Silence creates a rare opportunity to pause and drop into stillness, to become intimate with the mind ... When we start a journey to attune to our own minds by pausing into stillness we enter a realm of experience that can produce surprise in each moment. (p. 72)

Blanton (2007:216) introduces three questions to narrative practice, namely:

1. Is knowledge possible without language (perhaps questioning one of the assumptions of social constructionism above?).

2. Relying on stories from the past and the future, are stories adequate for capturing the present moment?

3. If we follow Drewery and Winslade (1997:42) suggesting that, 'We can only speak ourselves into existence within the terms or stories that are available to us', is it possible to contemplate a transcendent self?

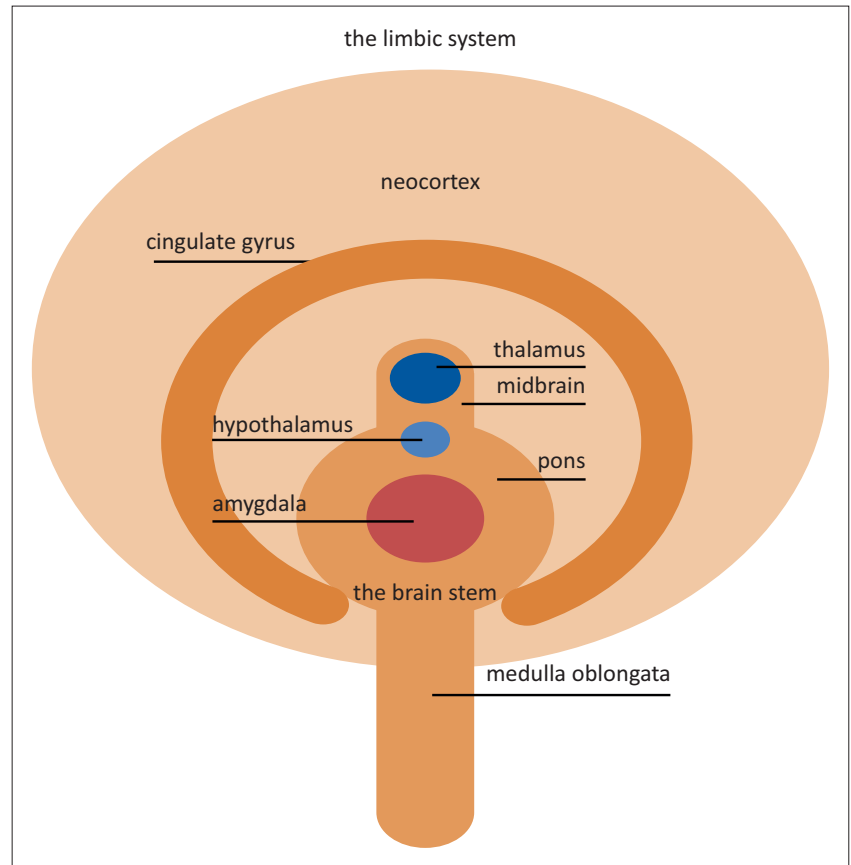

FIGURE 5: The basic brain.

In response to these, Blanton (2007) then suggests the following benefits of contemplative practice:

1. Stories become objects of awareness. Just as people become more aware of their thoughts through the process of contemplating, they also can gain greater awareness of their stories. This awareness helps people see that their stories are 'just stories', and not containers of truth, or reality.

2. Space develops between the story and the person. In contemplation, people learn to step back from thoughts and see that they are not their thoughts. In therapy, this skill translates into learning how to stand back from stories. In this space, people gain an awareness of another self - the transcendent self. This is the self that emerges in silence, when the storying-self is quieted. A narrative about this transcendent self may be difficult to put into words, but within the context of therapy, people have the opportunity to create a story that contains an enlarged view of the self.

3. Awareness of the present moment is heightened. Contemplation helps people experience the present moment. Narrative therapy points us towards the importance of experience, and narrative therapy also reminds us that many of our experiences are unnoticed and discarded. The contemplative tradition teaches that experience happens in the now. Contemplation helps people wake up to the experiences of the present moment. These newly observed experiences can then become the raw material for creating new stories (pp. 216-217).

Considering the benefits suggested above, it needs to be determined whether contemplative practice does indeed allow us to access the non-languaged centres of the brain. If we can succeed in doing that, we will have proven that 
contemplative practice can indeed be utilised to facilitate getting to the 'why'.

In an article published in 2013 which also describes the clinical benefits of contemplative practices, Kerr, Sacchet, Lazar, Moore and Jones, describe the cortical dynamics of contemplation. In this review article, through their sensoryattentional cognitive theory of mindfulness practice, they propose that a sequence of psychological abilities is achieved in mindfulness, including emotion perception, meta-cognition, and finally the release of attentional processes (Kerr et al. 2013:11). This they claim is achieved through a top-down alpha modulation in which the thalamic nucleus is involved. As is evident from Figure 5, the thalamus is part of the limbic system, which, if we follow the logic above seems to suggest that contemplative practice can facilitate access to the limbic brain, which is the centre governing intentionality and therefore getting us to 'why'.

\section{Potential applications}

In this article, the researcher tried to sensitise the reader to the potential that the theory developed here may apply equally well to personal and corporate transformational processes. Both in counselling and coaching processes, contemplative practice may complement narrative practice. In this regard the process of problem solution may be facilitated through the development of alternative life or identity stories. Clients may be assisted in utilising contemplative practices like mindfulness (Blanton 2007), meditation (Kerr et al. 2013), labyrinths (Bloos \& O'Conner 2002), reflective processes $^{4}$ (Amulya 2011) and mandalas ${ }^{5}$ (Zinn 1973) to access their intentionality. Once the hermeneutical bridge between problem-saturated activity or events and the implicit intentionality has been crossed, this newly-accessed intentionality will become the ground for alternative practice, which will be aligned with the intentionality of the client.

According to personal experience, when working with corporate clients, the theory developed in this article may serve to facilitate the various identity processes like change and transition, conflict mediation and resolution and culture development and change. Silence in this context can be facilitated through contemplative practices like labyrinths, facilitated reflection, engaging the soul of the workplace by means of approaches as suggested by Briskin (1998) and presencing (Scharmer 2009). The work done by Briskin, especially around role and images of company identity is

4.According to Amulya (2011:1-5), reflection is an active process of witnessing one's own experience in order to take a closer look at it, sometimes to direct attention to it briefly, but often to explore it in greater depth. This can be done in the midst of an activity or as an activity in itself. The key to reflection is learning how to take perspective on one's own actions and experience - in other words, to examine that experience rather than just living it. By developing the ability to explore and be curious about our own experiences and actions, we suddenly open up the be curibus about our own experiences and actions, we suddenly open up the possibilities of purposeful learning - derived not from books or experts, but from our work and our lives. This is the purpose of reflection: to allow the possibility of a disaster, a success, a relationship, or any other internal or external event, before, a disaster, a success, a relationship or after it has occurred.
during

5.Described as 'A mandala is a source of inspiration and contemplation that helps you to affirm and validate your connection to the bigger picture' (Johnson 2010). well worth investigating in this regard. It is also suggested that contemplation may be supported by settings which exclude bright light like sunshine and electric lighting ${ }^{6}$ (Winterson 2009:4).

Art may be another technology for accessing meaning and intentionality. Referring to the 'rat race' in the labour market mentioned previously, Wiley Hausam (2014) suggests that 'Art stops all of that and allows creative ideas to emerge almost on their own.' This issue of The Economist (Hausam 2014) continues to report how Stanford University is busy implementing concerted efforts to expose their students to arts, in order to address the question about where creativity comes from:

So, in much the same manner that Immanuel Kant, an 18thcentury philosopher, developed ideas on his daily walks through Königsberg in Prussia, Stanford students' outings into the world of arts will—so the university's leadership hope-help them become more creative citizens. (Hausam 2014)

Art in this sense may include practices like music, painting, sculpting and storytelling.

Another practice which may be considered in this regard is the ancient practice of pilgrimages. In this regard, refer to Heuertz (2010).

\section{Conclusion - Handing the conversation over ...}

Whether we are individuals or organisations, in our identity quests we may sometimes encounter ontological challenges. The challenges present themselves as conflicts between the events in our experienced worlds - the landscapes of action - within which we are positioned, and the implicit intentionalities of our landscapes of consciousness (Bruner 1986:14). In attempting to escape this ontological frustration, we often resort to alternative sets of action - without contemplating the intentionalities implicit to these actions. This may most often result in 'rearranging the deck chairs on the Titanic'!

If we do attempt to reflect on intentionality, we frequently experience difficulty in accessing it. In this article I indicated that this 'why' is governed by a non-languaged brain segment. This may explain the trouble we have in our languaged endeavours to find meaning. This then identifies the need for 'silent practice'. Contemplative practice was identified as such a practice, which functions in the same primitive or limbic brain system as intentionality. It is therefore suggested that contemplative practice should complement narrative practice in re-authoring our identity stories to become more agentive.

6.I have noticed that when all the lights are on, people tend to talk about what they are doing - their outer lives. Sitting round in candlelight or firelight, people start to talk about how they are feeling - their inner lives. They speak subjectively, they argue less, there are longer pauses. To sit alone without any electric light is curiously creative. I have my best ideas at dawn or at nightfall, but not if I switch on the creative. I have my best ideas at dawn or at nightfall, but not if I switch on the
lights - then I start thinking about projects, deadlines, demands, and the shadows lights - then I start thinking about projects, deadlines, demands, and the shadows
and shapes of the house become objects, not suggestions, things that need to be done, not a background to thought (Winterson 2009). 
In conclusion, other practices like art may now be investigated to determine whether their impact could facilitate access to the limbic system as well.

\author{
The Best in Art and Life \\ Roger Rosenblatt \\ The best in art and life \\ comes from a center \\ something urgent and powerful \\ an ideal or emotion \\ that insists \\ on its being. \\ From that insistence \\ a shape emerges \\ and creates its structure out of passion. \\ If you begin with a structure, \\ you have to make up the passion, \\ and that's very hard to do. \\ (Wheatley 2007:74)
}

\section{Acknowledgements Competing interests}

The author declares that he has no financial or personal relationship(s) that may have inappropriately influenced him in writing this article.

\section{References}

Amulya, J., 2011, 'What is reflective practice?', Community Science, May, 1-5. Benner, D.G., 2011, Soulful spirituality, Brazos Press, Grand Rapids.

Blanton, P.G., 2007, 'Adding silence to stories: Narrative therapy and contemplation', Contemporary Family Therapy 29, 211-221. http://dx.doi.org/10.1007/s10591007-9047-x

Bloos, I.D. \& O'Conner, T. St James, 2002, 'Ancient and Medieval labyrinth and contemporary narrative therapy: How do they fit?', Pastoral Psychology 5(4), 219-231. http://dx.doi.org/10.1023/A:1014097211429

Briskin, A., 1998, The stirring of soul in the workplace, Berrett-Koehler Publishers, Inc., San Francisco.

Bruner, J., 1986, Actual minds, possible worlds, Harvard University Press, Cambridge.

Drewery, W., 2005, 'Why we should watch what we say: Position calls, every day speech, and the production of relational subjectivity', Theory and Psychology 15(3), 305-324. http://dx.doi.org/10.1177/0959354305053217

Drewery, W., \& Winslade, J., 1997, 'The theoretical story of narrative therapy', in G. Monk, J. Winslade, K. Crocket \& D. Epston (eds.), Narrative therapy in practice: The archaeology of hope, pp. 32-52, Jossey-Bass, San Francisco.

Freedman, J. \& Combs, G., 1996, Narrative therapy: The social construction of preferred realities, WW Norton \& Company Inc., New York.
Freeman, W.J., 1994, Chaotic oscillations and the genesis of meaning in cerebral cortex, Springer Verlag, Berlin.

Freeman, W.J., 1995, Societies of brains, Lawrence Erlbaum Associates, Hillsdale.

Hausam, W., 2014, 'A Florence for the 21st century', The Economist, 2014, viewed 20 January 2014, from http://www.economist.com/blogs/prospero/2014/01/ stanford-university?fsrc $=\mathrm{scn} / \mathrm{fb} / \mathrm{wl} / \mathrm{bl} /$ aflorenceforthe21stcentury

Heuertz, P., 2010, Pilgrimage of a soul: Contemplative spirituality for the active life, InterVarsity Press, Downers Grove.

Iglovitz, J., 2001, 'Mind: The argument from evolutionary biology, (A very different kind of model)', viewed 16 January 2015, from http://www.foothill.net/ jerryi/ BIOLOGY8.pdf last

Johnson, M., 2010, 'Sacred Mandala art', viewed 16 January 2015, from http:// mjsacredliving.com/Sacred_Mandala_Art.html

Kabat-Zinn, J., 1990, Full catastrophe living, Dell Publishing, New York.

Kerr, C.E., Sacchet, M.D., Lazar, S.W., Moore, C.I. \& Jones, S.R., 2013, 'Mindfulness starts with the body: Somatosensory attention and top-down modulation of cortical alpha rhythms in mindfulness medititation', Frontiers in Human Neuroscience 7, 1-15. http://dx.doi.org/10.3389/fnhum.2013.00012

Kure, N., 2010, 'Narrative mediation and discursive positioning in organisational conflicts', Explorations: An E-Journal of Narrative Practice 2, 24-35.

Lester, A.D., 1995, Hope in pastoral care and counseling, Westminster John Knox Press, London.

Morgan, A., 2002, What is narrative therapy? An easy-to-read introduction, Dulwich Centre Publications, Adelaide.

Orwell, G., 1979, Animal farm, Penguin Books, Johannesburg.

Parry, A., 2009, 'Why we tell stories', viewed 15 August 2011, from http://www. familytherapy.org/documents/WhyWeTellStories.pdf

Pihlström, S., 2007, 'A meaningful life in a meaningless cosmos?: Two rival approaches', Cosmos and history: The journal of natural and social philosophy 3(1), 4-17.

Rankin, J., 2002, 'What is narrative? Ricoeur, Bakhtin, and process approaches', Concrescence 3, 1-12.

Scharmer, O., 2009, Theory U: Leading from the future as it emerges, Berrett-Koehler Publishers, Inc., San Francisco.

Siegel, D.J., 2007, The mindful brain, W.W. Norton \& Company, New York.

Sinek, S., 2009, Start with why: How great leaders inspire everyone to take action, Penguin Books, Johannesburg.

Tolle, E., 2009, A new earth - create a better life, Penguin Books, Johannesburg.

Webster, S., 2002, 'Spirituality: Providing guidance through uncertainty', in P.L. Jeffrey (ed.), AARE 2002: Problematic futures: Educational research in an era of uncertainty; Proceedings of the 2002 Australian Association for Research in Education conference, pp. 1-16, Australian Association for Research in Education, Coldstream

Wheatley, M.J., 2007, Finding our way: Leadership for an uncertain time, BerrettKoehler Publishers, San Francisco.

White, M., 2000, 'Re-engaging with history: The absent but implicit', ch. 3, in Reflections on Narrative Practices: Interviews and essays, Dulwich Centre Publications, Adelaide.

White, M., 2007, Maps of narrative practice, W.W. Norton, London.

Winslade, J., 2003, 'Narrative mediation: Assisting in the renegotiation of discursive positions', The International Journal of Narrative Therapy and Community Work 4, 64-75.

Winslade, J., 2006, 'Mediation with a focus on discursive positioning', Conflict Resolution Quarterly 23(4), 501-515. http://dx.doi.org/10.1002/crq.152

Winterson, J., 2009, 'Why I adore the night', The Guardian, 31 October, p. 4.

Zinn, G.A., 1973, 'Mandala symbolism and use in the mysticism of Hugh of St. Victor', History of religions 12, 317-341. http://dx.doi.org/10.1086/462685 